\title{
Evaluation of a call programme for cervical cytology screening in women aged 50-60
}

\author{
A J Robertson, G S Reid, C A Stoker, C Bissett, N Waugh, I Fenton, J Rowan, R Halkerston
}

\begin{abstract}
For many years Tayside has benefited from a successful opportunistic cytology screening programme. In recent years, however, the decrease in mortality due to cervical cancer has levelled off, with most cases of severe disease arising in women who have not been screened. In view of this the health board developed a new computer system for call and recall based on the community health index. This facility allowed the unscreened population to be identified and located on an individual general practice basis. The findings of the call programme in the $\mathbf{3 1 3 6}$ women aged 50-60 were studied. The 29 practices in Perth and Kinross participated in the scheme. Before the call started 4287 out of $7423(58 \%)$ women had been screened, and after the call programme this had risen to $5109(69 \%)$. Moreover, a further $1158(15 \%)$ women were identified who had a valid reason for exclusion from the programme. This meant that $6267(84 \%)$ women of the study population were accounted for by the system. The call programme in Tayside will be completed in 1989 and will include all women aged 20-60.
\end{abstract}

\section{Introduction}

The cervical cancer screening programme in the United Kingdom has failed to produce the distinct improvement in mortality and morbidity from cervical carcinoma seen elsewhere, especially in Canada, Scandinavia, and Iceland. ${ }^{12}$ Over 2000 women in England and Wales and around 200 in Scotland die each year from cervical carcinoma. ${ }^{3}$ To improve the service the government has directed health authorities and boards to introduce computerised call and recall screening programmes.

Tayside Health Board has had an active and successful opportunistic cervical screening programme since 1964. For 14 years this used a computer to recall women with previously negative smears every five years. Although the screening programme produced a steady decrease in mortality from cervical cancer initially, in recent years a plateau had been reached and, in common with findings elsewhere, ${ }^{4}$ most invasive carcinomas were arising in unscreened women.

A better system was clearly required to identify and invite unscreened women for a smear, and hence a new computerised system for cervical screening call and recall was developed by the health board. ${ }^{5}$ The new computer program was introduced in the recall mode in 1986, and in October 1987 Perth and Kinross unit laboratory, one of the two laboratories in Tayside performing cytological examinations, started the formal call of previously unscreened women. The call programme throughout Tayside will be completed in 1989 and will cover all women aged 20-60. The system is now also used by Fife and Forth Valley Health Boards.
We describe here our experiences with the new computer system and the outcome of the call programme in women aged 50-60. With the introduction of a call and recall programme to other areas in Scotland imminent our findings provide an indication of the workload that a call programme will produce and highlight some of the problems.

\section{Subjects and methods}

The Perth and Kinross unit laboratory serves a total population of 123000 with 7423 women aged 50-60. The area is predominantly rural but includes the city of Perth (population 42000) and several small towns. There are nine general practices in Perth and 20 elsewhere; all the practices participated in the screening programme.

The details of the computer program have been described in detail elsewhere. ${ }^{5}$ The system provides on line facilities for entering data and inquiries and is known as OCCURS (on line cervical cytology update and recall system). It is linked to the community health index database of up to date names and addresses of the population. The index provides a record for every person in the area who is registered with a general practitioner or has attended a hospital or outpatient clinic and generates a unique number used by both hospitals and primary care, thereby reducing the chances of duplication or misidentification. The index is constantly updated by both the hospital service and primary care and with details of deaths from the registrar general. There is no need, therefore, to have a separate file of names, addresses, and general practitioners for cervical cytology. The index system includes postcodes, and population analysis based on geographical distribution is therefore possible.

The first stage of a call is a computer search. The computer allows a lower age determinant to be set and uses the postcode facility to localise the call to the catchment area. It scans all the records of women aged between 60 and the age determined to see whether they have had a cervical smear and hence are already in the recall programme. Those women who have not been screened previously according to the computer records are identified and the number in the age group is indicated. This procedure allows the laboratory to gauge the likely workload from any particular call run and, if necessary, to reset the age limit to produce a smaller or greater number of women to be called.

If the number of women identified is acceptable the computer is instructed to initiate a call. It prints a list of women with their current addresses in order of the general practices; at the same time a batch of preprinted adhesive address labels is generated. The labels are sent to each practice, which checks the details and confirms that they are correct. Any alterations to addresses are noted and the index files amended. The general practitioners also inform the laboratory of any
Correspondence to: $\mathrm{Dr}$ Robertson.

$\operatorname{Br}$ Med $\mathcal{f}$ 1989;299:163-6 
women who are believed not to require a smear (for example, those who had had a hysterectomy for a benign condition), and these details are entered into the computer's cytology files. A standard letter of invitation for a smear is available for the general practitioner that is designed to accommodate the adhesive address label. The general practitioners are encouraged to use this and to suggest a time of appointment. Some of the general practitioners, however, use their own letter, and others choose to contact the women by telephone. A health education pamphlet has been designed to accompany invitations to screening.

If no smear is received within three months from the women who remain in the call programme a repeat address label is generated and the general practitioner again contacts the woman. After a further four months a list of the remaining non-respondents is printed by the computer and sent to the consultant cytopathologist. A standard duplicated letter is sent to the woman using a preprinted address label, with a copy to her general practitioner, inviting her to make an appointment for a smear with either her general practitioner, or the local well woman clinic, details of which are included. The well woman clinic has female medical staff, and this is indicated in the default letter. The health education pamphlet is enclosed with this final attempt at persuading the woman to attend for a smear. The letter is sent on a "return to sender if not delivered" basis, and the local post office has cooperated with the scheme, ensuring that as much accurate information is available on the addresses of non-respondents as is practicable. This scheme allows the laboratory to be confident that all relevant women have received an invitation for a smear.

A small number of women on the index are not registered with a general practitioner. They are sent a letter and health education pamphlet direct from the pathologist, suggesting that they make an appointment with the well woman clinic.

As older women are at increased risk of having undetected invasive squamous carcinoma and respond poorly to opportunistic screening programmes the call programme was started for women aged 60 and has been working down the age ranges in instalments. The data presented in this paper are for women aged 50-60, who are covered in four groups (50-53, 54 and 55, 56 and 57 , and 58-60).

\section{Results}

The figure shows the rate of response to the call invitation in two groups aged 58-60 and 56-57. There was a good response to the first call and a fair response to the second but only a minimal further response to the default letter issued by the pathologist. In the recall programme the default letter was found to have a more important role and produced a greater response (unpublished data).

Altogether there were 7423 women in Perth and Kinross in the study population, of whom 4287 $(57 \cdot 8 \%)$ had previously had a smear and were in the recall programme. The remaining 3136 women comprised the initial population for the call programme. We found, however, that $1158(36.9 \%)$ of these women had an appropriate reason for exemption. Hence there were 1978 women who required a smear, of whom 822 had a smear taken: this represented $41 \%$ of those eligible.

In summary, before the call programme was started $58 \%$ of the study population were in the recall system, and after the call programme $84 \%$ of the population (6267 women) had been satisfactorily accounted for (those in the recall system plus those in the call programme having a smear plus the exempt population). When only those women having a smear were considered the proportion rose from $58 \%$ to $69 \%$.

A total of 1158 women were excluded from the call prcgramme, accounting for $16 \%$ of the original total study population. Of this group, $778(67 \%)$ had left the area, though they were still on the index; $59(5 \%)$ had had a smear elsewhere, and $94(8 \%)$ were women for whom a smear was clinically unwarranted. Interestingly, $227(20 \%)$ women were found to have had a hysterectomy for benign conditions (this information was confirmed, wherever possible, through the local files on surgical histopathology).

Table I shows the response to the call programme in Perth compared with elsewhere. The 3298 women

TABLE I - Summary of response to call programme for cervical cytology screening in Perth and elsewhere in Perth and Kinross unit. Figures are numbers (percentages) of women

\begin{tabular}{|c|c|c|c|}
\hline & & Perth & Elsewhere \\
\hline Total study population & & $3298(44 \cdot 4)$ & $4125(55 \cdot 6)$ \\
\hline In recall programme & & $1988(60 \cdot 3)$ & $2299(55 \cdot 7)$ \\
\hline In call programme: & & $1310(39 \cdot 7)$ & $1826(44 \cdot 3)$ \\
\hline Exempt & 420 & 738 & \\
\hline Smeared & 338 & 484 & \\
\hline $\begin{array}{l}\text { Women who had had smear after } \\
\text { call programme }\end{array}$ & & $2746(83 \cdot 3)$ & $3521(85 \cdot 4)$ \\
\hline
\end{tabular}

living in Perth were covered by nine general practices, all located centrally, and hence there was little geographical, social, or ethnic variation among the practice populations. The 4125 women living in the small towns and rural areas were served by 20 general practices. Although a slightly higher proportion of women in Perth than elsewhere were in the recall programme, the response to the call programme was slightly better in the rural areas such that the cover in Perth and elsewhere became similar.
Rate of response per week (in women actually having smear) to invitation to smear programme in women aged 58-60 and 56-57

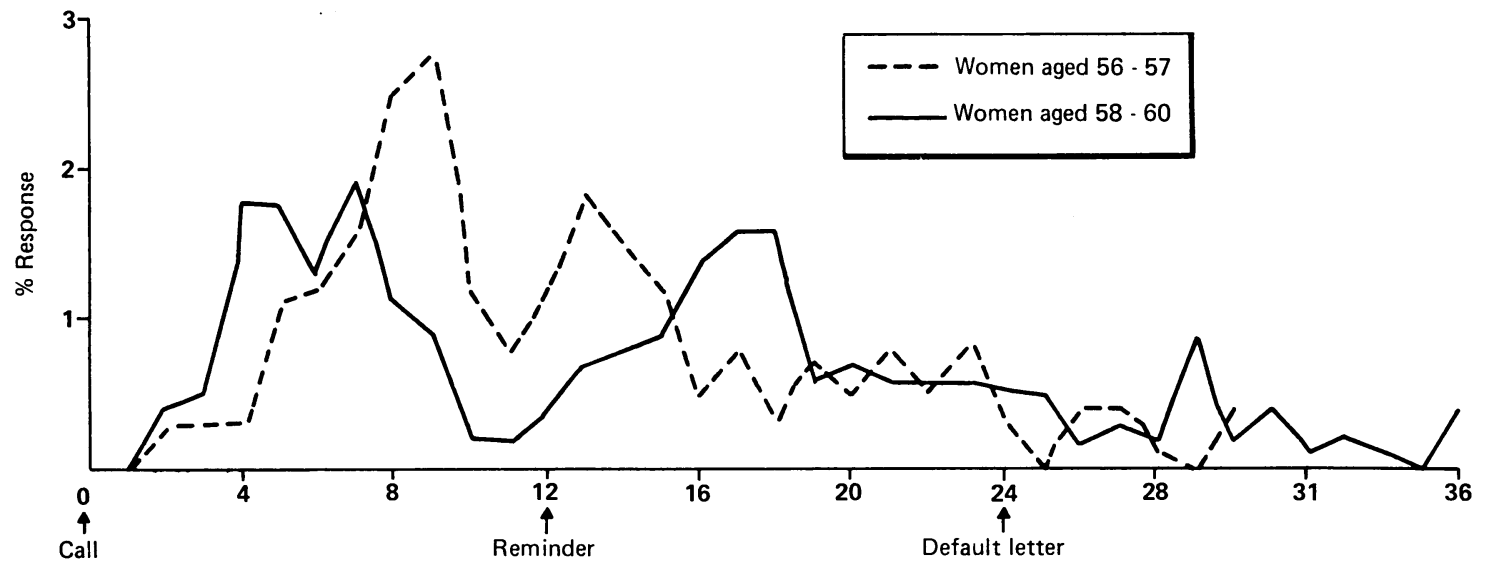

Weeks from call invitation 
TABLE II-Current diagnosis in 67 women with abnormal results of smears from call programme for cervical cytology screening

\begin{tabular}{lccc}
\hline Result of smear & $\begin{array}{c}\text { No of } \\
\text { women had colposcopy }\end{array}$ & $\begin{array}{c}\text { No who had } \\
\text { (No of women) }\end{array}$ \\
\hline $\begin{array}{c}\text { Mild squamous cell } \\
\text { dyskaryosis }\end{array}$ & 51 & 5 & $\begin{array}{c}\text { CIN grade II } \\
\text { and human } \\
\text { papillomavirus (1) } \\
\text { CIN grade III (2) }\end{array}$ \\
$\begin{array}{c}\text { Moderate squamous } \\
\text { cell dyskaryosis }\end{array}$ & 5 & 5 & $\left\{\begin{array}{l}\text { CIN grade II (1) } \\
\text { CIN grade III (5) } \\
\text { CIN grade III and } \\
\text { microinvasion (2) } \\
\text { Invasive squamous } \\
\text { carcinoma (3) }\end{array}\right.$ \\
$\begin{array}{c}\text { Severe squamous cell } \\
\text { dyskaryosis }\end{array}$ & 11 & 11 & \\
\hline
\end{tabular}

$\mathrm{CIN}=$ Cervical intraepithelial neoplasia

When we examined the statistical returns for each general practice (unpublished data) we found that the mean percentage cover after the call programme was $83 \%$ (range $66-100 \%$ ). When the practices with small numbers of patients in the study population were excluded, however, the range of cover was $66-95 \%$.

Of the smears taken, 735 (90\%) were within normal limits or showed only minor inflammatory changes; 20 (2\%) were unsatisfactory; and the remainder showed various grades of squamous dyskaryosis, most of these $(51(6 \%))$ being only mild. No cases of severe glandular atypia were found in this group of women.

Table II shows the current state of the patients with dyskaryotic smears. There were 16 cases of moderate or severe dyskaryosis: seven had cervical intraepithelial neoplasia grade III diagnosed histologically after colposcopy; two had cervical intraepithelial neoplasia grade III with microinvasion; three had invasive squamous carcinoma; and one had cervical intraepithelial neoplasia grade II. Of the remaining three women, one showed only immature squamous metaplasia and inflammation, and the two others had severe atrophy of the cervix and are receiving oestrogen treatment before reassessment. The 51 women with mild squamous dyskaryosis are continuing to be assessed, but cervical intraepithelial neoplasia grade II and human papillomavirus infection was diagnosed in one at colposcopy. The four other women who underwent colposcopy had distinctly atrophic cervixes, and one is receiving oestrogen treatment before further colposcopic examination.

\section{Discussion}

Few studies have been done on the outcome of formal call programmes in the United Kingdom, and these have been predominantly limited to a single general practice, where the interest and enthusiasm of the general practitioner could well be expected to produce a better overall response than would be the case in an unselected group. Houghton reported a $60 \%$ response for all age groups in a rural practice in Buckinghamshire $^{6}$; Meadows reported $87 \%$ cover in the 30-59 age group in a single city practice in $\mathrm{Bristol}^{7}$; and Ridsdale reported $87 \%$ cover in the $36-60$ age group in a two partner practice in Surrey. ${ }^{8}$ Shroff et al recently described their experiences with a call programme in a general practice in Paddington, with $30 \%$ cover after two years in women aged 20-64.

The only study in the United Kingdom that has examined a call programme with multiple general practices is that of Havelock et al. ${ }^{10}$ They reported recently their preliminary findings in what is to be a five year study of women aged 20-64 in east Berkshire. Only 43 of the 51 practices in their area were willing to cooperate in the study initially, and this had fallen to 33 within the first year. This contrasts with our experience in which all general practices participated and are continuing to do so. There was a $7 \%$ increase in the proportion of women undergoing smears in Berkshire, which is less than the $11 \%$ achieved in Perth and Kinross. Presumably, this reflects the greater overall cooperation of the general practitioners in our study. We are convinced that much of the success of our programme is related to the closer integration of primary care services with the hospital services in Scotland compared with the family practitioner committee system in England and Wales. We found some variation in the initial response of general practitioners to this scheme, which to some extent reflected their state of readiness to cooperate administratively. Many practices had to reorganise their internal staffing and administration to participate in the programme, but most have now done this, and we are not aware of any major problems as described by Shroff et al. ${ }^{9}$

The inaccuracy of the family practitioner committees' lists of patients, which will form the basis of the screening programmes in England and Wales, has recently been highlighted. "Various studies have shown that an eighth to a third of non-respondents to postal invitations for a smear had moved address and hence did not receive an invitation. ${ }^{12-16}$ Possibly general practice staff should be used to update the family practitioner committees' lists. In our study we found that $10 \%$ of the call population were not at the address on the index and were excluded from the programme. The community health index population register was developed in Tayside and is currently being adopted as a national system in Scotland. Hence if a woman moves within Scotland she will automatically be picked up by her new local call scheme. If a woman for whom a smear has yielded an abnormal result moves to England or Wales information eventually becomes available on the index about the new health authority and a letter is sent to the authority, advising it that the woman has moved to its area whom we believe needs a repeat smear. As already indicated the index has the inherent advantage of continual upgrading by information from not only primary care but also the hospital service and the registrar general. We believe, therefore, that the index system provides a satisfactory basis on which to establish the cervical and breast screening programmes.

We have been pleased with the success of the call programme in that we have achieved an $84 \%$ coverage of the study population. This is similar to the outcome of studies in single general practices. ${ }^{78}$ In a call study done recently for a large local employer in Perth the total cover of women age $20-60$ was also $84 \% .{ }^{17}$ This is the cover we can probably expect on completion of our full call programme. The government plans to alter the method of funding general practitioners for taking cervical smears from an item of service payment to a system that sets target cover figures of initially $60 \%$ and eventually $80 \% .^{18}$ Although all our practices achieved the lower figure, only two thirds achieved cover of more than $80 \%$, despite their active cooperation in the scheme.

We remain concerned that $16 \%$ of our at risk women have still not had a smear even after rigorous attempts to attract them into the programme. Our system has been designed to take account of most of the currently recognised factors that are said to detract women from attending such as ignorance of the test, ${ }^{19}$ fear of the test and the disease, ${ }^{20}$ lack of female staff to take the smear, ${ }^{21}$ inconvenient location and time of testing, ${ }^{22}$ and failure to receive an invitation. ${ }^{23}$ Evidently further studies of this non-respondent group are required to see whether the delivery of the service can be improved to accommodate their needs.

We thank Professor J Swanson Beck for his encouragement with this study and our general practitioner colleagues and their staff for their continuing support.

1 Hakama $M$. Trends in the incidence of cervical cancer in the Nordic countries. In: Magnus $\mathrm{K}$, ed. Trends in cancer incidence, causes and practical implications. Washington: Hemisphere, 1982:279-92. 
2 Worth AJ. The Walton report and its subsequent impact on cervical cancer screening programmes in Canada. Obstet Gynecol 1984;63:135-9.

3 Office of Population Censuses and Surveys. Trends in cancer mortality 1951-80. London: HMSO, 1983. (Series DHI No 11.)

4 Macgregor JE. Taking uterine cervical smears. Aberdeen: Aberdeen University Press, 1981. (British Society of Clinical Cytology publication.)

5 OCCURS Group. Computerisation of screening for cervical cancer. Health Bull (Edinb) 1988;46:146-52

6 Houghton H. Response to cervical screening. A survey of tested and untested women in one Buckinghamshire practice. Medical Officer 1968;120:334-7.

7 Meadows P. Study of the women overdue for a smear test in a general practice cervical screening programme. f $R$ Coll Gen Pract 1987;37:500-3.

8 Ridsdale LL. Cervical screening in general practice: call and recall. $f R$ Coll Gen Pract 1987;37:257-9.

9 Shroff KJ, Corrigan AM, Bosher M, Edmonds MP, Sacks D, Coleman DV. Cervical screening in an inner city area: response to a call system in general practice. $\mathrm{Br}$ Med $\mathcal{F}$ 1988;297:1317-8

10 Havelock CM, Webb J, Queenborough J. Preliminary results of a district call scheme for cervical screening organised in general practice. $\mathrm{Br} \mathrm{Med} \mathrm{J}$ 1988;297:1384-6.

11 Bowling A, Jacobson B. Screening: the inadequacy of population registers. BrMed f 1989;298:545-6.

12 Scaife B. Survey of cervical cytology in general practice. $\mathrm{Br}$ Med $\mathcal{J}$ 1972;iii: 200-2.

13 Sansom CD, MacInerney J, Oliver V, Wakefield J, Yule R. Recall of women in a cervical screening programme: an estimate of the rate of response. British Journal of Preventive and Social Medicine 1975;29:131-4.

14 Fraser RC, Clayton DG. The accuracy of age-sex registers, practice medical records and family practitioner committee registers. $\mathcal{J} R$ Coll Gen Pract 1981;31:410-9.

15 Fraser RC. Patient movements and the accuracy of the age-sex register I $R$ Coll Gen Pract 1982;32:615-22.

16 Eardley A, Elkind AK, Spencer B, Hobbs P, Pendleton LL, Horan D. Attendance for cervical screening-whose problem? Soc Sci Med 1985; 20:955-62.

17 Reid G, Halkerston R, Robertson A J. Is there a need for a place-of-work cervical smear service? Health Bull (Edinb) 1988;46:153-5.

18 Secretaries of State for Health, Wales, Northern Ireland, and Scotland. Working for patients. London: HMSO, 1989. (Cmnd 555.)

19 King JB. It's silly but I just don't want to know. Health Services 1983;11:13. 20 Spencer JT. A survey of cervical smear testing in general practice. Practitioner 1967;198:274-80.

21 Saunders J, Snaith AH. Cervical cytology consent rate. Lancet 1969;ii:207.

22 Sansom CD, MacInerney J, Oliver V, Wakefield J. Differential response to recall in a cervical screening programme. British foumal of Preventive and Social Medicine 1975;29:40-7.

23 Allman ST, Chamberlain J, Harman P. The national cervical cytology recall system: report of a pilot study. Health Trends 1974;6:39-41

(Accepted 17 April 1989)

\section{Wellcome Unit for the}

History of Medicine,

University of Cambridge, Cambridge

John Gabbay, MB, teaching associate

Correspondence to:

Academic Department of Epidemiology and

Community Medicine,

St Mary's Hospital Medica

School, London W2 1NY.

BrMed f 1989;299:166-9

\section{Clinical medicine in revolution: $2-$ Fusion in the crucible}

\author{
John Gabbay
}

The night of 13 July 1789 found several hundred medical and surgical students among the crowds thronging the streets of Paris in search of weapons and supporters.' After the next day's events doctors continued to be among the most active revolutionaries, both in the National Assembly and in the many local groups. ${ }^{12}$ The committees set up in the early constitutional phase of the revolution to deal with the grievances of the public were flooded with evidence of the dire effects of poverty, not least on health. The reformist physicians, such as Pierre-Jean-Georges Cabanis, Joseph Ignace Guillotin, Félix Vicq D'Azyr, and Antoine-François Fourcroy, seized the opportunity to push forward grand plans for reforms of medical science, education, and practice as the key to public health. ${ }^{14}$ Their proposals were based on many of the ideas discussed in last week's article. The Société Royale de Médecine, for example, under Vicq D'Azyr, laid before the committee of health in 1790 a new plan for a properly educated, egalitarian, unified medical and surgical profession, whose members would work in the countryside as well as in reorganised city hospitals. The profession would tackle the nation's

\section{"Medicine" became a non-word}

By now the more radical politicians who wanted to abolish all the academies, colleges, and charitable institutions were gaining the upper hand. The charities were disbanded, the universities shut down, medical degrees abolished, and academicians derided. ${ }^{12}$ After war was declared in 1792 and the radical Girondins and later the Jacobins assumed control the reformist professionals could only keep their heads down (if they were to keep their heads at all) as their institutions and ideas came under attack during the Terror. Indeed, even their vocabulary, redolent of the privileges of the ancien régime, was now full of non-words - for example, academies became societies, the Hôtel-Dieu became the Hospice de l'Humanité, and doctors became health officers. In the month of Thermidor, Year Two of the republic (even the old calendar had been swept away), formal medical education was abandoned and anyone with a desire to practise health (medicine was also a non-word) had merely to apply for a licence. Those with an aptitude, cried the hardline radicals, would soon learn what was really needed to heal the sick and would be free from the overcomplicated useless medical theories that had merely led society away from natural healing. By the same token 